\title{
EL MERCOSUR Y EL PROCESO SUDAMERICANO ANTE LA SEGUNDA DÉCADA DEL SIGLO XXI. ¿HACIA UNA CONSOLIDACIÓN DEL NUEVO REGIONALISMO ESTRATÉGICO?
}

\author{
Mercosur and the South American process facing the second decade of \\ the XXI century. Is it a consolidation of the new strategic regionalism? \\ Lincoln Bizzozero Revelez ${ }^{1}$ \\ Universidad de la República, Montevideo, Uruguay.
}

Recibido: 18 de marzo de 2011. Aprobado: 7 de septiembre de 2011.

\section{RESUMEN}

El artículo analiza la evolución de Mercado Común del Sur (Mercosur), su vinculación con la Unión de Naciones Sudamericanas (Unasur) en la primera década del siglo XXI y examina las bases sobre las que se asienta el regionalismo sudamericano. Para el análisis se plantean dos cuestiones relevantes para las relaciones internacionales y la economía política: las capacidades que tienen los Estados en el marco de los debates sobre la gobernanza mundial y la transición del sistema internacional y el papel del Estado en el desarrollo. Se considera que es necesario tomar distintos niveles de análisis que involucran al Estado como articulador entre el ámbito local-nacional y el regional, que a su vez potencia ese espacio al ámbito internacional y mundial. En ese sentido, la política internacional de Brasil, el eje estratégico con Argentina a nivel regional y el papel que juega en la articulación de esos niveles posibilitan visualizar las características y evolución del regionalismo sudamericano.

PALABRAS CLAVE: Mercosur, Unasur, regionalismo estratégico.

$1 \quad$ Licenciado en Ciencia Política (Relaciones Internacionales) de la Universidad Libre de Bruselas, Bélgica; máster en Promoción al Desarrollo de la Universidad de Amberes, Bélgica, y doctor en Ciencia Política de la Universidad Libre de Bruselas. Actualmente es investigador del Programa de Estudios Internacionales de la Facultad de Ciencias Sociales de la Universidad de la República, Montevideo, y profesor del Instituto Artigas de Servicio Exterior, Uruguay. Correo electrónico: lbizzozero@gmail.com 


\begin{abstract}
The article analyzes the evolution of Mercosur and its connection with the Union of South American Nations (Unasur) in the first decade of the century and examines the foundations of South American regionalism. The analysis raises two important issues for international relations and political economy: states' capacities for participation in discussions on global governance and in the transition of the international system, and the role of the State in development. It was considered necessary to conduct a multilevel analysis of the State as an articulator of local-national and regional spheres that in turn empowers these spheres in international and global arenas. In that regard, Brazil's foreign policy, its strategic alliance with Argentina at the regional level, and its coordinating role at those levels provide a view of the characteristics and evolution of South American regionalism.
\end{abstract}

KEYWORDS: Mercosur, Unasur, strategic regionalism.

\title{
I. INTRODUCCIÓN
}

El Mercado Común del Sur (Mercosur), como otros procesos de integración regional que se iniciaron o se reformularon en la década de 1990, surgió en un contexto determinado por el fin de la bipolaridad del sistema internacional y el empuje que produjeron diferentes acontecimientos, entre los cuales se encuentra el mismo derrumbe del sistema socialista, en la aceleración de la mundialización del capitalismo. Este fenómeno de aceleración del tiempo histórico provocó diversas repercusiones y cambios en los Estados y en los demás actores del sistema internacional. La desestructuración del mundo bipolar existente hasta el momento y la eclosión de posibilidades que planteó al mercado la ampliación del espacio, posicionaron al Estado frente a una nueva realidad en el escenario internacional.

Ante ese nuevo escenario internacional de los 90 del siglo XX, se plantearon dos cuestiones relevantes a los Estados. Desde la perspectiva de las relaciones internacionales, las capacidades en función de los recursos de poder, de impulsar o participar de procesos (régimen internacional) conducentes a conformar un nuevo orden. La mayor parte de los Estados del planeta no estaba en condiciones de impulsar o participar del proceso de transición, por lo que se bosquejaron respuestas diversas, de mayor o menor adaptación o autonomía. La segunda cuestión relevante que se plantearon los Estados atañe a la eco- 
nomía y política del desarrollo, una vez que dejaron de confrontarse modelos excluyentes y pasó a considerarse el papel del Estado en su relación con el mercado mundial (BernalMeza 2008). Esta cuestión, que hasta los años 90 correspondía a la esfera de los "asuntos internos" y que estuvo vinculada a las esferas de influencia que le deparaba la posición del país en el conflicto bipolar, pasó a ser un componente de la agenda interméstica por el efecto de la mundialización y de la progresiva incorporación de los temas sociales en la agenda política y estatal.

Los regionalismos que surgieron en los 90 fueron respuestas que diseñaron los Estados frente al proceso de mundialización. Desde el momento en que la economía, propulsada por las empresas transnacionales, extendía sus fronteras, la respuesta de los Estados contempló diversas formas de acuerdos regionales y de generación de nuevas instancias y realidades económicas (Hettne 1994; Hettne, Inotai y Sunkel 2000). Como han señalado algunos análisis, hubo un eje divisorio entre los Estados impulsores del proceso de respuesta a la mundialización, en la tríada Estados Unidos-Europa-Japón y el resto de países que procesaron diversas respuestas regionales en torno a esas tres áreas económicas (Axline 1996).

Estados Unidos impulsó la regionalización latinoamericana-caribeña a través de diversas iniciativas continentales, entre las cuales se encuentra la Iniciativa para las Américas, que presentó el Presidente George Bush (padre) en 1990. Por otra parte, desde fines de los 80 varios gobiernos de la región propulsaron reformas liberales en el marco del Consenso de Washington, conjunto de propuestas y medidas que constituyeron el credo del modelo neoliberal. Los procesos regionales que se gestaron o reformularon en los 90 tuvieron como base gobiernos orientados por ese modelo, que apoyaron los postulados del nuevo regionalismo, en particular referidos a la apertura exterior y la liberalización de la economía.

Mercosur, acuerdo regional de Argentina, Brasil, Paraguay y Uruguay con vistas a conformar un mercado común, surgió en ese contexto impulsado por gobiernos liberales. La conformación de Mercosur generó una doble respuesta: de inserción competitiva y también estratégica, desde el momento en que Brasil (y en menor medida Argentina) fueron impulsores del mismo. En otros términos, desde el momento en que para los socios grandes, y en particular para Brasil, Mercosur se definió como política exterior del Estado frente al proceso de mundialización, la propuesta de regionalismo abierto se planteó en el marco del Estado como una respuesta estratégica. Esto significa que la decisión de conformar el bloque regional de Mercosur no importó solamente en términos estratégicos por el acuerdo del Estado con las empresas a los efectos de la inserción competitiva, 
sino que también por la importancia que se le otorgó a la participación del Estado en la arquitectura y contenidos del nuevo orden internacional. ${ }^{2}$

La creación de Mercosur fue funcional a la política internacional de Brasil y también de Argentina, ya que posibilitó canalizar demandas internas vinculadas al escenario mundial. Para Brasil, el proceso regional significó entre 1991 y 1994 la única iniciativa de política industrial y la posibilidad para la diplomacia de pasar de una situación reactiva a una activa con el apoyo de una parte del sector empresarial. ${ }^{3}$ Por otra parte, las políticas exteriores de Argentina y Brasil convergieron en esa propuesta de regionalismo, en la medida en que constituyó una respuesta desde la región a las iniciativas de libre comercio provenientes de Estados Unidos, sin caer en enfrentamientos, que cuestionaran la cooperación bilateral (Hirst 2009).

La crisis y estancamiento de Mercosur entre 1998 y 2003, y el inicio de un proceso de cooperación regional en América del Sur en el siglo XXI, replantearon la validez, la estrategia y el alcance del proceso regional de Mercosur. Por otra parte, dependiendo de las respuestas a estos puntos, surge un tema relevante que atañe a la articulación entre Mercosur y la Unión de Naciones Sudamericana. Una de las cuestiones que se han esbozado con el proceso regional sudamericano es la posibilidad de que Mercosur se termine licuando en el proceso sudamericano que tiene entre sus objetivos generar una convergencia de políticas en algunos temas sensibles (defensa, ambiente, seguridad regional, cooperación fronteriza). Al ser Brasil el socio articulador de ambos emprendimientos, un tema relevante que se plantea tiene relación con sus capacidades en la gobernanza regio-

2 De esta manera, la decisión de conformar un bloque regional adquiere su estatuto de estratégico, en función de las políticas exteriores de los Estados y del impacto que genere el bloque regional, y no solamente del objetivo, y repercusiones que genera el bloque en sí. Es claro que hay dos niveles a considerar: el nacional y el regional, pero ambos son relevantes a la hora de la definición de estratégico del regionalismo. Esto significa que Mercosur no es estratégico solamente por la alianza Estado-empresas transnacionales y nacionales por el proceso de internacionalización de las actividades económicas (Briceño 2006), o bien porque el bloque desarrolla una política económica internacional a los efectos de conseguir ventajas en el mercado para un grupo de países (Deblok y Brunelle 1993), o porque el acuerdo regional genera un desvío de comercio en función del desarrollo de algunos sectores clave. Estas consideraciones son importantes a la hora de visualizar el comportamiento del bloque vis-à-vis el entorno internacional, pero no llega a contemplar la globalidad del fenómeno del Estado y su participación en la gestación del nuevo orden.

3 Es ilustrativo en lo que concierne a la relación política industrial y política regional el artículo de Pedro da Motta Veiga "Brasil en Mercosur: influencias recíprocas" en Riordan Roett (comp) (1999) Mercosur: Integración regional y mercados mundiales Buenos Aires, Nuevo Hacer - Grupo Editor Latinoamericano. En lo que concierne a la relación entre las políticas exteriores de Argentina y Brasil con las políticas en Mercosur, véase el artículo de José Augusto Guilhon "La nueva geometría del poder mundial en las visiones argentina y brasileña" en Felipe de la Balze (comp) (2000) El futuro del Mercosur. Entre la retórica y el realismo Buenos Aires, Consejo Argentino para las Relaciones Internacionales, Asociación de Bancos de la Argentina.

218 Si Somos Americanos. Revista de Estudios Transfronterizos 
nal y también global. El concepto de gobernanza tiene diversas acepciones y es utilizado con distintos alcances. Se refiere en este trabajo, en sintonía con el origen de la palabra (governance del inglés) a las nuevas formas de coordinación que trascienden las políticas estatales nacionales. Si bien el concepto alude a una superación del eslabón nacional, también hace referencia a trascender las políticas estatales (coordinación jerárquica y vertical) a través de la inclusión de los actores sociales (coordinación social y horizontal). De esta manera, las capacidades de algunos Estados de otorgar determinados contenidos a la construcción regional no solamente constituyen un componente sistémico de adaptación, sino también resultan un recurso específico de poder, que se refleja en distintas formas de gobernanza (Camargo 1999; Messner 2000).

Este artículo pretende responder a estos puntos. Se parte de la base de algunos supuestos que han sido desarrollados en trabajos anteriores del autor. Entre ellos, que los cambios de gobierno en los países de la región han modificado la agenda política y regional, y por ende también los contenidos del regionalismo (Bizzozero 2003, 2007a, 2009a). A su vez, como el principio de funcionamiento de este regionalismo se afinca en la cooperación regional, sobre la base de las prioridades de cada Estado, debido al doble efecto de la transición estructural del sistema internacional y la crisis del modelo neoliberal en la región sudamericana, se producen pocos resultados positivos en la macropolítica del bloque, aunque se sigan generando diversos avances y espacios en la micropolítica regional (Bizzozero 2007b).

Por otra parte, se considera que la construcción regional sudamericana es funcional al rol de Brasil en el escenario global, pero que el buen desempeño en el tablero global requiere de al menos algunos resultados (buena gobernanza) en el espacio sudamericano y regional (Bizzozero 2009b). Finalmente se considera que este nuevo regionalismo "estratégico" es impulsado por Brasil y en diferente o menor medida por otros Estados. Ello surge de los beneficios que surgen de la regionalización de la cooperación, de la articulación de diversos ámbitos de desarrollo regional a través del Integración de la Infraestructura Regional Sudamérica (IIRSA) y de la construcción (aún endeble) de instituciones. De ahí que por su identidad y características del proceso, Brasil no asuma un liderazgo regional y a su vez, los otros países, aun reconociendo el papel de Brasil, no terminen de concederle ese papel (Bizzozero 2009c).

Este conjunto de supuestos tiene una lógica vincular que posibilita analizar el proceso regional de Mercosur y el referido al regionalismo sudamericano en un marco conceptual que enfatiza el papel del Estado y las regiones en los cambios del sistema internacional y del capitalismo. La comprensión de esta articulación resulta ineludible para 
analizar los fenómenos que se están viviendo. De esta manera, se enfatiza la importancia que tiene Brasil como articulador de Mercosur y del espacio sudamericano, pero al mismo tiempo se visualiza que el estancamiento del proceso regional en función de nuevos contenidos resulta funcional a Brasil en tanto referente global del espacio regional. Esta situación de cambios y estancamiento del bloque regional del Mercosur y de diseño de los contenidos de Unasur sin instrumentos para efectivizar los mismos, no debería mantenerse por mucho tiempo. En definitiva, Brasil podrá continuar siendo el articulador de ambos espacios y responder de manera funcional a la globalización, pero deberá necesariamente propulsar resultados regionales con vistas a la gobernanza global. Por otra parte, los demás socios regionales, que también cuentan, pueden generar insumos para una construcción regional o no hacerlo, y con ello retrasar los tiempos de una gobernan$z a$ regional. Finalmente se plantea el tema de la agenda de la región y los actores de la sociedad civil nacional-regional ( $y$ a veces regional-nacional), que generan sus propias dinámicas, influyendo en la macropolítica regional y, a veces, acelerando las definiciones y propulsando la gestación de nuevas instancias y situaciones. ${ }^{4}$

El trabajo continuará de la siguiente manera. En el punto siguiente se presentará a Mercosur en sus antecedentes y orígenes, y se vincularán los mismos con la respuesta de adaptación al cambio de contexto internacional, a los efectos de generar condiciones para la inserción competitiva. Esa respuesta fue también estratégica para Argentina y Brasil, en la medida en que la política exterior expresó las prioridades nacionales. Esta respuesta regional se enmarcó en el regionalismo abierto, conjunto de postulados que no pudieron terminar de plasmarse en los 90, ya sea porque mostraron limitaciones ideológicas o directamente porque fueron cuestionados y revisados con la crisis del modelo "neoliberal".

Con posterioridad se expondrá la evolución reciente de Mercosur con el objetivo de visualizar los cambios que se han concretado en el proceso regional y los contenidos de los mismos. Las prioridades y cuestiones de la agenda regional de Mercosur se han modificado durante el siglo XXI como consecuencia de un agotamiento del modelo de "regionalismo abierto". En este apartado se presentarán algunas de las principales modificaciones del nuevo regionalismo estratégico en relación al de los años 90. Los cambios de la agenda regional no han definido una nueva dinámica, lo cual implica, entre otras

4 La inclusión de la sociedad civil y de la agenda es lo que posibilita "rupturas" y "desenlaces inciertos" en procesos regionales como el de Mercosur, que tienen entre sus objetivos el mercado común y a su vez requieren de legitimidad social, en sociedades que en las últimas décadas han generado espacios de mayor participación. Como el nivel de análisis es nacional-regional y a veces regional-nacional (incluso local), debe entenderse que el "desenlace" o la "ruptura" puede provenir de un ámbito nacional o local y expresarse en lo regional. 
cosas, plantearse el papel de Brasil, de su eje con Argentina y de la gestación de la Unión de Naciones Sudamericanas como forma de superación del estancamiento.

Luego se presentará la Unión de Naciones Sudamericanas (Unasur), en tanto expresión actual del regionalismo sudamericano y de articulación con el espacio global. Se expondrán los principales problemas que surgen del camino recorrido en la gestación de Unasur, desde que se iniciara el proceso sudamericano en este siglo, los cuales involucran a Brasil por el papel central que juega dicho país.

Por último se exponen algunas reflexiones finales sobre el proceso regional de Mercosur con vistas a la segunda década del siglo XXI, sobre su vinculación con Unasur como parte de los desafíos del proceso regional sudamericano y el papel de Brasil en la articulación de los espacios nacional-regional-sudamericano (y latinoamericano-caribeño) y global.

\section{LOS INICIOS DEL MERCOSUR: LAS BASES DEL REGIONALISMO ABIERTO}

Mercosur es un proceso de integración que se inició por parte de Argentina, Brasil, Paraguay y Uruguay en 1991. El tratado fundacional, el Tratado de Asunción, fue firmado el 26 de marzo de 1991. Mercosur tiene como objetivos la libre circulación de bienes, servicios y factores productivos, la adopción de un arancel externo común y de una política comercial común y la coordinación de políticas macroeconómicas y sectoriales entre los Estados parte.

Los inicios de ese proceso regional pueden explicarse por diversos factores que convergieron históricamente a inicios de la década de 1990. En primer lugar resulta relevante la acumulación generada por los antecedentes históricos comunes de los países, la doctrina internacionalista latinoamericana, el pensamiento de la CEPAL, el proceso regional de la Asociación Latinoamericana de Libre Comercio y lo que generaron las ideas de algunos políticos y pensadores (Devés 2003).

En segundo término, la resolución del conflicto argentino-brasileño por las represas, pero sobre todo la culminación de una lógica competitiva por el predominio del espacio geopolítico y el pasaje a un proceso de cooperación. Este pasaje a un proceso de cooperación terminaba con una forma de relaciones entre los países, que era triangulada 
por Estados Unidos, sobre todo con posterioridad a la Segunda Guerra Mundial (Cervo 1994; Herrera 1995; Moniz 2004).

En tercer lugar, el cambio en las relaciones bilaterales argentino-brasileñas generó otra dinámica bilateral entre los actores y a su vez posibilitó la concreción de un acercamiento entre los países democráticos de la región a los efectos de concertar políticas. El cambio en las relaciones al realizarse conjuntamente con las transiciones democráticas, facilitó una transformación de las bases sobre las cuales se fue edificando la aproximación cooperativa, ya que posibilitó la participación a los actores políticos, sociales y también se generaron espacios para los flujos de personas (y no solo de bienes) y concomitantemente de las ideas. Por otra parte, las transiciones democráticas en Argentina, Brasil y Uruguay fomentaron una modificación en la cooperación regional en el conjunto de América Latina, posibilitando la gestación del Grupo de Río, en la medida en que se fue estableciendo una necesaria vinculación entre el régimen democrático, la cooperación y los procesos de integración y la manifestación de las políticas exteriores con el sistema internacional.

Para comprender los orígenes y la evolución del proceso regional resulta necesario introducir, además del análisis bilateral específico, las relaciones de ambos países con Estados Unidos como actor principal del sistema internacional e interamericano. En ese sentido, una de las cuestiones que resultan relevantes es la "permisividad" de Estados Unidos para con el proceso regional del Mercosur, la cual se asentó en dos pilares: la aceptación de los gobiernos participantes del bloque del marco de reformas propuesto por el Consenso de Washington y de la Iniciativa para las Américas. La Iniciativa para las Américas, que fuera presentada por George Bush (padre) en 1990, tenía dos componentes: el político, en el cual el Presidente de Estados Unidos enfatizó el objetivo de que esta región sería la primera democrática del planeta; y el comercial, que centraba en Estados Unidos el eje motor de la región con múltiples canales, tantos como países del área interamericana.

El surgimiento del Mercosur se afirmó sobre la base de una convergencia política de los gobiernos en las reformas económicas a implementar y su vinculación con el proceso de integración. De esa manera, la apertura de las economías se vinculó con las reformas del Estado y del mercado, y de ahí que el Mercosur fuera funcional a los temas de la agenda continental pautados por el Consenso de Washington. En ese sentido, el Mercosur nació y desarrolló el denominado regionalismo abierto, conjunto de postulados que preconizaban una liberalización completa regional, una apertura unilateral, la posibilidad de fijar una preferencia arancelaria regional a los efectos de desarrollar en algunos sectores economías de escala, la "reciprocidad de derechos y obligaciones" entre los socios, y una institucionalidad controlada por los gobiernos, que contara con una mí- 
nima "burocracia" regional. Además de esos postulados de base, el regionalismo abierto implicaba acordar una política comercial común frente a terceros, una política de competencia, reglas comunes en materia de normas de origen, salvaguardas, servicios, inversiones, propiedad intelectual, compras gubernamentales, una convergencia macroeconómica que posibilitara la transformación productiva y la coordinación en algunos sectores clave para posibilitar la integración como la energía y el transporte. ${ }^{5}$

Estos postulados no fueron cumplidos en su totalidad por el Mercosur. La falta de cumplimiento se debió a diversos tipos de cuestiones. En algunos casos se trató de haber alcanzado un techo en materia de cooperación y convergencia regional como evidenciaron las relaciones argentino-brasileñas; en otros se evidenciaron las asimetrías en términos de responsabilidades y costos del proceso, como fue el caso sobre todo con los socios pequeños; o también las diferencias entre las prioridades de las agendas difíciles de ser compatibilizadas en función de los condicionantes externos, como fue el caso de la crisis del "real" hacia fines del siglo pasado. Además se plantearon como explicaciones complementarias o alternativa de la falta de aplicación de los postulados del "regionalismo abierto" de los 90, la ausencia de la denominada "voluntad política" en temas estratégicos que requerían más tiempo para los países del bloque (al menos para algunos) y la insuficiencia de recursos humanos calificados, de instituciones y "burocracias" organizadoras a los efectos de ir generando una nueva cultura regional.

Una cuestión relevante que ayuda a comprender las dificultades en la transición para ese "nuevo regionalismo" de los 90, es que el proceso regional no contó con el tiempo suficiente para "regionalizar la agenda internacional". De esta manera, al "internacionalizarse" los temas que requerían de políticas comunes, en agendas de negociación externas (Área de Libre Comercio de las Américas "ALCA", negociaciones con la Unión Europea), se alejaron de la cotidianeidad de los sistemas políticos y de las sociedades nacionales. La internacionalización de algunos temas sensibles aparejó evidentes riesgos de estancamiento en las negociaciones, por los antecedentes de los países latinoamericanos que han confrontado a partir de una cultura periférica, con un relativo grado de desarrollo en materia económica y de las ideas. Por otra parte, en el caso de Argentina y Brasil, esa cultura se enriquece con una anterior generación de normas e instituciones, que necesariamente son puestas como referentes para que se defina una negociación de las pautas de convergencia.

5 Ciertos análisis incluyen algunos de los postulados, pero dejan de lado justamente parte de los que han sido más sensibles y definitorios del proceso (reciprocidad, no inclusión de temas sectoriales, políticas comunes, mínima institucionalidad). En ese sentido, justamente lo que importa son los postulados heredados que estructuralmente condicionan el momento actual. 
La inclusión de los gobiernos de la región en los parámetros del Consenso de Washington y las definiciones en materia de las políticas exteriores de los países posibilitaron que la "permisividad" de Estados Unidos en los inicios del Mercosur, continuara durante la etapa de transición. En ese sentido es necesario comprender que Estados Unidos empezó a manejar una respuesta política en distintos niveles frente a la región durante esa primera etapa. Por un lado, la definición de los temas relevantes de la agenda continental para el reconocimiento del proceso, lo cual quedó plasmado en el Acuerdo $4+1$, que planteó un marco para el comercio e inversiones. En segundo lugar, la continuidad de las relaciones bilaterales con los países, que permitía el manejo de la "última carta" para eventualmente estimular posibles "salidas" del bloque. Finalmente, una mayor injerencia en asuntos financieros, con las implicancias que ello aparejó en la credibilidad y sustento para un proceso de integración regional.

El apoyo inicial al Mercosur, la enunciación de un Programa de Liberalización Comercial en el mismo anexo al Tratado de Asunción y la inclusión de un cronograma de actividades, definieron los pilares esenciales sobre los cuales se asentó el éxito inicial del proceso. Para ello, los gobiernos utilizaron positivamente el marco regional para impulsar las reformas a nivel nacional. Este conjunto de reformas nacionales tuvieron que ver de manera notoria con lo que constituye la esencia de una zona de libre comercio (disminución de aranceles a cero, esclarecimiento de las normas no arancelarias, pero también rotulación de productos, caracterización de forma de los bienes, características de contenido, transparencia comercial, mejor eficiencia aduanera, entre otros).

La definición inicial del Mercosur como regionalismo abierto, tuvo como consecuencia su participación, con posterioridad a la ratificación del Protocolo de Ouro Preto en 1995 y su consiguiente reconocimiento de la personalidad jurídica internacional, en instancias birregionales de negociación con la Unión Europea e interamericanas en el ALCA, propulsando una concepción del bloque en tanto respuesta estratégica. Ello implicó una articulación entre el plano político -el bloque en el sistema internacional-, el plano económico -inserción competitiva y regulación- y el social -participación de la sociedad civil. La crisis económica que se inició hacia fines de los 90 dejó sin cumplir varios de los postulados del regionalismo abierto, además de déficit en la dimensión política, sobre todo en el plano institucional, y en la dimensión social. ${ }^{6}$

El estancamiento y crisis del bloque a partir de 1998 posibilitó que comenzara a cuestionarse el mismo en tanto vehículo para el desarrollo y también para el ejercicio de

6 Lo cual no quiere decir que el Mercosur no tuviera esa dimensión social, pero la misma fue insuficiente, tanto en las políticas regionales como en la participación de la sociedad civil (Mellado 1998). 
un instrumento de poder en las relaciones internacionales. El declive de la concepción del Mercosur, vinculada con un modelo de regionalismo abierto, coincidió con los inicios de este siglo y milenio que comenzó con dos acontecimientos ordenadores de la coyuntura desde una perspectiva global: la Ronda del Milenio de la Organización Mundial del Comercio (OMC) y los atentados del 11 de septiembre, que retroalimentaron desde el centro imperial de Estados Unidos varios temas vinculados a la seguridad (nacional y regional), el terrorismo, la guerra y la paz, los derechos humanos.

Cuatro factores explican la reorientación del Mercosur: la crisis regional, y en especial de Argentina y Uruguay, que llevó a que los países se plantearan como prioridad la resolución de la misma; los cambios de gobierno vinculados con la necesidad de transformaciones y que contempló las demandas políticas y sociales representativas de los nuevos tiempos; el impulso dado por Brasil al espacio sudamericano en la política regional y la adaptación del Mercosur a esa prioridad; finalmente, el papel que comenzó a jugar Venezuela en el escenario regional, que se expresó a través de objetivos, criterios e instrumentos de cooperación (Malamud 2007).

El punto siguiente expondrá las transformaciones ocurridas en el bloque regional del Mercosur con los cambios de gobierno, que se expresaron a partir del Programa 20042006 y en otras decisiones que muestran una modificación de prioridades que otorgan otro contenido al regionalismo estratégico, diferente al que se recorriera durante los años 90, desde el momento en que prioriza la agenda política y social y el interés nacionalregional. Sin embargo, este camino, como se verá, todavía no ha logrado plasmar los resultados que se requieren para una gobernanza regional desde el momento en que algunos de los países otorgan prioridad al interés nacional sin una contraprestación en el ámbito regional.

\section{EL MERCOSUR DEL SIGLO XXI: NUEVAS BASES PARA UN REGIONALISMO POSMODELO NEOLIBERAL}

El bloque regional del Mercosur inició el siglo XXI con cambios de gobierno en Argentina y Chile que posibilitaron un acercamiento con Brasil y la posibilidad de implementar una "tercera vía" en la región. ${ }^{7}$ Esta opción quedó sin posibilidades de mani-

7 La Tercera Vía se planteó como posibilidad en la región por la afinidad ideológica con esa opción entre los Presidentes de Argentina, Fernando de la Rúa; de Chile, Ricardo Lagos; y de Brasil, Fernando Henrique Cardoso. La afinidad ideológica posibilitó una convergencia política y algunos primeros pasos en lo que se conoció como el "relanzamiento" del bloque en la dirección de priorizar la dimensión social. 
festarse por la crisis en Argentina y posteriormente en Uruguay entre fines del 2001 y el 2002. Sin embargo, algunos hitos que marcaron la transición entre la década de los 90 y el siglo XXI en la orientación del regionalismo (y por ende también marcaría los contenidos futuros) fueron: la realización de la Cumbre de Brasilia en el año 2000, que dio inicio al proceso de cooperación sudamericano; la constatación por parte de Fernando Henrique Cardoso de que era necesario pasar a una lógica endógena de prioridades ante el agotamiento de las negociaciones en el frente externo; y el inicio de la etapa de relanzamiento del Mercosur, asociada a la finalización de la etapa "comercial", y el ingreso de prioridades del ámbito político y social.

La Cumbre de Presidentes de América del Sur, que se realizó en Brasilia, en el contexto de las conmemoraciones de los 500 años del descubrimiento de Brasil, delimitó dos aspectos importantes sobre el regionalismo y las negociaciones de espacios diferentes: el que se refiere a la necesaria articulación entre la consolidación de los procesos regionales y el conjunto de América Latina y Caribe; y el que tiene relación con la importancia de la identidad sudamericana en el cruce de procesos y espacios diferenciados. Por otra parte, la Cumbre fue la ocasión en que Brasil explicitó sus prioridades, el papel a cumplir, las vías e instrumentos a aplicar en el proceso regional. ${ }^{8}$

La Cumbre reafirmó tres pilares para la seguridad y el desarrollo de la región: la paz, la democracia y la profundización de la integración. De esta manera, la Cumbre de Brasilia marcó varias definiciones sobre el regionalismo en un proceso de construcción de distintos espacios, niveles y alcances de realización. Lo que importa destacar es que se afirma el inicio de un espacio sudamericano sui géneris que a su vez se afinca en la cooperación regional, que tiene como objetivo la construcción de la región sudamericana (lo cual implica determinados acuerdos y políticas regionales).

Por otra parte, la afirmación del Presidente de Brasil Fernando Henrique Cardoso, de partir de una lógica endógena que implicara una definición de prioridades para consolidar y profundizar el proceso y al mismo tiempo seguir avanzando en el Mercosur global, se da en el momento que se planteó un agotamiento del proceso de las instancias de negociación internacional. ${ }^{9}$ De esta forma, el Mercosur quedó confrontado a sus propias opciones en un momento de dificultades financieras, sin que pudiera gestarse una

8 La invitación del Presidente de Brasil fue hecha a los Presidentes de América del Sur, lo cual explicita la prioridad continental de Brasil. Véase al respecto el artículo de Luis Bilbao (2000) "Brasil tentado por una opción sudamericana" Le Monde Diplomatique II (13).

9 Fernando Henrique Cardoso realizó esas afirmaciones con motivo de la XVII Cumbre del Mercosur, que se realizó en Montevideo, en diciembre de 1999. 
lógica activa de relanzamiento del proceso, cuyo impulso debía venir fundamentalmente desde Brasil (Bizzozero 2001).

Finalmente, durante los primeros meses del 2000, los cambios de gobierno en Argentina y Chile, y la proximidad política de los Presidentes Ricardo Lagos, Fernando Enrique Cardoso y Fernando de la Rúa, mostraron un nuevo dinamismo en materia de iniciativas y propuestas para aportar en la región, entre las cuales se encuentra la inclusión de una mayor apertura a la dimensión social. ${ }^{10}$

Con posterioridad, los cambios de gobierno en los países de la región y la reorientación del eje de cooperación estratégico argentino-brasileño propulsaron la idea de un nuevo impulso en el bloque regional a partir de la redefinición de las prioridades, la inclusión de temas y la resolución de otras cuestiones. La aprobación del Programa de Trabajo 2004-2006, a iniciativa de Brasil, contempló las principales asignaturas pendientes de la agenda, los objetivos y las líneas de resolución e incluyó algunos temas pendientes y no contemplados durante la década de los 90 . Entre los temas incluidos en el bloque regional a partir del Programa de Trabajo 2004-2006, que no estuvieron contemplados en la década de aplicación del regionalismo abierto, se encuentran el de las asimetrías entre los países y en el desarrollo regional, la generación de fondos estructurales, la articulación productiva y algunos temas pertenecientes a la nueva agenda social y económica como el apoyo a las pequeñas y medianas empresas, los referidos al mundo rural, la soberanía alimentaria.

La evolución del bloque regional en los últimos años exhibe un cambio en los temas de la agenda regional, la inclusión de cuestiones no contempladas anteriormente, la generación de nuevas instancias institucionales, de fondos regionales (estructurales y sectoriales), el apoyo a la pequeña y mediana empresa y el énfasis en proyectos de articulación productiva y en innovación en ciencia y tecnología. Algunos ejemplos de estos desarrollos son: la definición de una estrategia del bloque de crecimiento del empleo; la aprobación del sistema de pagos en moneda local; la creación de la Reunión de Altas Autoridades sobre Derechos Humanos; y la aprobación y puesta en marcha del Parlamento regional; la creación del Fondo para la Convergencia Estructural del Mercosur (Focem), del Fondo Educacional del Mercosur, del Fondo de Apoyo a Pequeñas y Medianas Empresas involucradas en iniciativas de integración productiva y del Fondo de Agricultura

10 Ricardo Lagos en una visita oficial que realizó a Fernando de la Rúa, planteó la necesidad de incluir en la agenda el tema social y firmó además una declaración conjunta y una Carta Social. La proximidad política de los tres gobiernos planteó la posibilidad de la Tercera Vía en el espacio sudamericano. La crisis en Argentina a fines del 2001 y el cambio de gobierno en Brasil terminaron rápidamente con una experiencia que en los hechos no implicaba una opción. 
Familiar del Mercosur (FAF-MERCOSUR); la aprobación del Programa de Integración Productiva con siete líneas de acción a nivel horizontal y dos a nivel sectorial (foros de competitividad e iniciativas de integración).

En términos de la macropolítica regional, estos desarrollos no han sido suficientes, al menos hasta el momento, para generar otra dinámica de funcionamiento, que posibilite la resolución de algunos de los temas sensibles que obstaculizan la marcha del bloque. Entre los mismos se cuentan algunos, que fueron tratados con sendas decisiones, en la última reunión del Consejo Mercado Común, que se realizó en San Juan, Argentina. La aprobación del Código Aduanero del Mercosur (Decisión 27/10), la eliminación del doble cobro del Arancel Externo Común y distribución de la renta aduanera (Decisión 10/10), la aprobación del Documento Único Aduanero (Decisión 17/10), la puesta en vigencia del Manual de Valor Aduanero (Decisión 16/10), la reglamentación del Fondo para la Convergencia Estructural del Mercosur (Decisión 1/10) y la resolución del financiamiento para algunas propuestas, son algunas de las cuestiones que preparan las bases para una nueva etapa en el funcionamiento del bloque. Quedan planteadas de todas formas otras cuestiones relevantes en el funcionamiento del bloque que se remiten a la reforma institucional del Mercosur, al trato de las asimetrías, a la incorporación nacional de las decisiones aprobadas, a la definición de acuerdos en las negociaciones externas, al déficit de participación social en el ámbito regional, a la continuidad de las lógicas nacionales en la resolución de los temas sensibles de las agendas domésticas cuando se expresan en la región, y a lo que podría denominarse la regionalización de políticas atinentes a la ciencia, tecnología e innovación para propulsar la sociedad del conocimiento.

La relación entre determinados temas relevantes de la macropolítica regional y los avances gestados exponen realidades diferentes que aparejan consecuencias negativas para los socios pequeños, para determinados sectores que aspiran a una mayor apertura en la ventana regional y para quienes proyectan una región con mayor inclusión, conocimiento y capacidades en ciencia y tecnología. Algunas de las explicaciones que posibilitan comprender esta dinámica diferenciada en el espacio regional, entre las realizaciones en algunos sectores y la falta de avances en los objetivos del Tratado, son: el escaso tiempo pasado para la definición de resultados, las prioridades de Brasil de continuar avanzando a pequeños pasos con vistas a seguir articulando los niveles nacional-regional y global, y lo que suele argumentarse como la razón fundamental: el ingreso de las prioridades definidas por la agenda doméstica, sin que se definan posibles canales de retorno desde el nivel nacional al regional.

Los tres factores explicativos de los pocos avances en los objetivos del bloque y en la generación de resultados de impacto en la macropolítica regional posibilitan una com- 
prensión en las dificultades de pasaje del nivel nacional al regional en las políticas públicas (Luján 2009). Este punto, que resulta crucial en cualquier proceso regional que tenga como objetivo un mercado común, atañe siempre la dilucidación de una ecuación entre el contexto internacional y el eje impulsor del bloque. ${ }^{11}$ En el caso del Mercosur, el mantenimiento de los temas principales en la agenda regional y el avance a pequeños pasos son funcionales para la estrategia global y sudamericana de Brasil, mientras que esa misma evolución posibilita que Argentina centre sus prioridades en la definición bilateral con el socio mayor de los temas de la agenda, entre los que se incluyen los productivos y comerciales.

Como en definitiva no importan tanto los factores explicativos de una situación, que en este caso se trata de la evolución y estrategia del bloque regional, sino de los contenidos que van definiendo las bases futuras de funcionamiento, importa visualizar si efectivamente puede hablarse de un nuevo regionalismo del bloque regional.

Con independencia de la perspectiva que se adopte, puede señalarse de por sí que el bloque regional se encuentra efectivamente en una nueva etapa con prioridades temáticas diferentes, aun cuando se mantienen las asimetrías estructurales y los problemas derivados de la falta de acuerdo en determinados principios de funcionamiento (Caetano 2009). Este primer escalón explicativo se complementa con otro que enfatiza un cambio en el ordenamiento de prioridades y en el ámbito desde el cual se parte en las negociaciones externas. En lo que concierne el ordenamiento de prioridades, el acuerdo de un Mecanismo de Integración y Cooperación Bilateral (MICB) entre Argentina y Brasil, suscrito en noviembre del 2007, consolida las bases de funcionamiento de este nuevo modelo estratégico regional, desde el momento en que incluye algunas áreas sensibles como política exterior, energía, infraestructura, tecnología, transporte, industria y defensa. En lo que se refiere al punto de partida en las negociaciones externas del bloque, en esta etapa se prioriza el ámbito nacional (e incluso local y sectorial-nacional) al regional para posteriormente llegar al internacional, invirtiendo la secuencia que se diera durante la etapa de consolidación entre 1995 y fines de siglo.

Como este nuevo modelo no ha terminado de consolidarse, se plantean diversos interrogantes sobre la evolución del bloque regional, las posibilidades de "flexibilización" del mismo para los socios, en particular los pequeños, las capacidades de Brasil en im-

11 El eje impulsor del Mercosur es el que tienen Argentina y Brasil. Eso no quiere decir que pueda emularse al eje franco-alemán que impulsó la integración europea. Hay varias diferencias, entre las cuales una de ellas es la ubicación de cada eje en la estructura del sistema internacional: uno en el centro y otro en la periferia. De esta ubicación estructural se derivan varias consecuencias que marcan las diferencias entre ambos ejes y por ende también entre los procesos. 
pulsar el proceso regional articulando el bloque con el espacio sudamericano en función de la participación en la gobernanza global, o bien, desde una perspectiva minimalista, un estancamiento y dilución del bloque sobre la base de la inercia y la primacía de los intereses domésticos nacionales sin puntos de encuentro en el espacio del Mercosur.

La respuesta a estos interrogantes tienen que ver con la resolución de las contradicciones que se procesan en el contexto internacional en términos de la gobernabilidad del sistema y en el sistema capitalista. Como la gobernabilidad del sistema internacional atañe también a los procesos regionales y la gobernanza, es decir, a la forma como participan los distintos actores en los diferentes espacios, importa visualizar el papel de articulador que cumple Brasil entre el ámbito regional, el sudamericano y el global.

\section{UNASUR: ¿EXPRESIÓN INTERGUBERNAMENTAL O INSTANCIA DE GOBERNANZA REGIONAL?}

La realización de la primera Cumbre de la Unión de Naciones Suramericanas (Unasur) en Salvador de Bahía, en diciembre del 2008, luego de la aprobación del Tratado Constitutivo en Brasilia, en mayo, concretó una vía del espacio sudamericano que expresa en sus objetivos reivindicaciones de la agenda política y social de distinto tenor. Unasur es una síntesis de las distintas propuestas y caminos planteados, y un catalizador de una nueva etapa del regionalismo sudamericano en el escenario global.

El Tratado Constitutivo de la Unasur es el resultado de un debate sobre los alcances y contenidos del regionalismo en esta etapa, que se plasmaron en las negociaciones entre Brasil y Argentina por una parte y por la otra de Venezuela, donde estuvieron en la mesa las distintas concepciones y enfoques a desarrollar. Las definiciones alcanzadas descartaron algunas opciones que propiciaran un avance conjunto en materia de políticas comunes y tuviera un alcance regional, que trascendiera en algunos temas y sectores las políticas nacionales. Ello se patenta en los instrumentos, recursos y estructura institucional del Tratado constitutivo, que en definitiva consolida un ámbito de concertación político, que tiene como objetivo propiciar la cooperación entre los distintos Estados, con una institucionalidad que dependerá de la diplomacia presidencial en última instancia (Cimadamore y Rodríguez 2008).

La opción concertada posibilita un acuerdo sobre la base de un común denominador para todos los Estados, aun cuando se planteen divergencias ideológicas y estratégicas sobre el camino a recorrer (Ruiz 2008). En definitiva, se priorizó darle continuidad 
a una propuesta de desarrollo regional, donde hay intereses estatales y empresariales, lo cual a su vez otorga un marco institucional mínimo para la concertación de las políticas frente al exterior y la convergencia en políticas e instancias regionales entre los distintos países (Giacalone 2005).

En su expresión actual, Unasur posibilita un marco regional para el intercambio de experiencias e información, la supervisión de los procesos políticos (véase el ejemplo de Bolivia), de los temas negativos de la agenda regional (narcotráfico, desastres naturales, problemas fronterizos, recursos naturales), la articulación de posiciones comunes de temas regionales en las instituciones e instancias internacionales y la continuidad de emprendimientos que posibiliten un determinado desarrollo de los países y la región en el marco del sistema regional sudamericano. La conformación de la Reunión de Ministros de Defensa y los acuerdos a los que se llegó muestran que el marco regional posibilita el desarrollo, en materia de intercambio y cooperación, sin desmedro de las prioridades nacionales, lo cual planteará lógicas limitaciones luego de que se recorran las primeras instancias.

Lo que importa destacar es que Unasur y el regionalismo en América del Sur, expresa el interés de la política internacional de Brasil en su proyección política global y en el desarrollo regional. En la medida en que Unasur retoma los antecedentes del IIRSA y potencia los mismos, contribuye al desarrollo nacional-regional. A su vez, como Unasur se proyecta como el ámbito de dilucidación diplomático de conflictos y de temas regionales, de legitimación de un espacio de seguridad regional y de expresión de la diversidad cultural plantea en términos prospectivos una modificación del ámbito de decisión de los temas regionales. De esta manera, Unasur pasa a ser parte de las prioridades regionales de Brasil conjuntamente con el Mercosur, cuya base es la alianza estratégica con Argentina (Vigevani y Ramanzini jr. 2009). Sin embargo, cada espacio tiene su lógica, objetivos e instrumentos específicos, por lo que cada uno de ellos tiene su especificad en la política internacional de Brasil y en las instancias negociadoras.

El desarrollo del espacio nacional-regional ha provocado diversas tensiones y conflictos como consecuencia de varios factores, entre los cuales resultan fundamentales dos: el vinculado con el creciente protagonismo de Brasil y de empresas brasileñas en la conformación de un marco y de una infraestructura regional, y el referido a las diferencias en los modelos de desarrollo y de integración de los países.

El primer factor en el incremento de los diferendos, atañe específicamente a la manifestación regional de la política exterior de Brasil, y concierne a asuntos fronterizos, la utilización de recursos naturales compartidos y las consecuencias sociales y ambienta- 
les de proyectos regionales en la implementación de la IIRSA. Algunas manifestaciones recientes de estos diferendos son: las reivindicaciones de Paraguay en renegociar los términos del Tratado de Itaipú; los conflictos con Bolivia por la renegociación de los términos contractuales en la explotación de gas natural y el papel de Petrobrás; las denuncias del gobierno de Ecuador de incumplimiento de contrato por parte de la constructora Odebrecht; la suspensión del pago de la deuda externa por considerarla ilegal y por el desempeño de Petrobrás en la extracción y exploración de petróleo, debido a los impactos sociales y ambientales y además por los perjuicios económicos ocasionados. ${ }^{12}$

El segundo factor de conflictos concierne las prioridades y orientaciones de los gobiernos en los procesos de integración y en función del modelo de desarrollo. En este rubro, las diferencias que se han expresado han resquebrajado las bases de una convergencia en los distintos procesos. Si se toman en cuenta los conflictos bilaterales en los últimos años, varios de ellos están vinculados con Colombia y Perú, países que se han pronunciado abiertamente por un tratado de libre comercio (TLC) con Estados Unidos.

Los dos factores de conflictos -el vinculado con las prioridades de política exterior de los países y con los modelos de desarrollo y la manifestación de Brasil y sus empresas en los proyectos regionales diversos- señalan los límites del equilibrio de Brasil en tanto Estado - región. UNASUR potencia a Brasil en el plano global en la perspectiva de asumir un lugar en la gobernanza, pero para ello requiere conducir y legitimarse a nivel regional. A su vez, Unasur expresa y es uno de los componentes del nuevo regionalismo estratégico, en la medida en que pretende responder a través de la concertación de políticas y la cooperación regional desde el interés nacional, a temas de interés nacional-regional y regional-nacional como lo son el desarrollo, la defensa, los recursos naturales entre otros.

En definitiva, Unasur es el ámbito de representación del espacio regional sudamericano y se potencia como ámbito regional de la globalización/regionalización y de representación regional en la gobernanza. La articulación entre el espacio regional del Mercosur y Unasur potencia a Brasil en tanto Estado-región, pero apareja al mismo tiempo la dimensión de los desafíos en la transición del sistema internacional y en la construcción del nuevo orden.

12 El ministro de Relaciones Exteriores de Brasil, Celso Amorim, tomó muy seriamente la decisión del gobierno de Ecuador de no pagar la deuda externa por considerarla ilegal. La decisión de no transferir 30.6 millones de dólares para el pago de los intereses de los Bonos Global 2012 concernían un préstamo realizado por el Banco Nacional de Desarrollo Económico y Social (BNDES). El préstamo fue firmado de acuerdo con las reglas del Convenio de Pagos y Créditos Recíprocos (CCR) de la Asociación Latinoamericana de Integración, de acuerdo a lo señalado por el ministro en la Comisión de Relaciones Exteriores y Defensa Nacional. Véase La Onda Digital, en sitio: http://www.laondadigital.info/LaOnda/LaOnda/420/A2.htm 


\section{MERCOSUR: HACIA UN NUEVO REGIONALISMO ESTRATÉGICO EN EL SIGLO XXI}

El Mercosur, en su versión actual, ha modificado la agenda regional con la inclusión de temas que el "regionalismo abierto" no había considerado en sus postulados y con una modificación de prioridades temáticas. La agenda regional sin embargo no ha posibilitado un quiebre del estancamiento en la macropolítica regional, aun cuando todavía es muy pronto para evaluar algunos de los cambios que se procesaron. De todas formas, algunos de los postulados diferentes del nuevo regionalismo estratégico, más centrado en la cooperación, en la agenda doméstica y en la definición de prioridades que partan del ámbito nacional (e incluso local) para luego pasar al ámbito regional y de ahí a otros hasta llegar al global, trasuntan una manera diferente de encarar los delicados temas de la gobernabilidad y la participación en la gobernanza.

Una de las cuestiones fundamentales en un proceso de integración regional es la generación de instituciones y políticas regionales reconocidas. Esto quiere decir que los países deben ponerse de acuerdo en ciertos principios y además en la protección de determinados bienes públicos regionales. Para ello, el modelo anterior de "regionalismo abierto" ya no tiene respuestas, por lo que los cambios en las prioridades de la agenda regional y la inclusión de otras cuestiones, resulta un primer paso necesario, aunque no definitivo para la generación de un "derrame" institucional y político en la región.

En ese sentido, Brasil puede jugar un papel relevante, aunque también no exclusivo, debido a que hay otros países que juegan. En esta categoría de los países que juegan a nivel regional, se encuentra Argentina, que ha ido concretando una alianza estratégica cuyas bases han sido ajustadas en el siglo XXI, en relación a los años 90 . El eje brasileñoargentino no es el único que importa en América del Sur, pero es el soporte básico para propiciar un proceso de cooperación sudamericano que cuente con distintas salidas articuladoras. La cuestión es que los ajustes de la primera década del siglo XXI se deberán actualizar y eventualmente reajustar o modificar a inicios de la segunda década. Esto surge de los cambios de gobierno que se darán en los dos países, primero en Brasil y posteriormente en Argentina, y además por los condicionantes que surgen del escenario internacional pautado por negociaciones en distintos ámbitos que no terminan de "cerrarse", mostrando las dificultades que se generan en la transición del sistema, cuando a su vez actúan condicionantes sistémicos que aceleran el tiempo histórico.

Es justamente la alianza estratégica de Brasil con Argentina la que ha planteado un modelo de cooperación regional bilateral, pero a su vez ha posibilitado la gestación 
del espacio sudamericano regional, proyecto que involucra en primer lugar a Brasil como principal país que tiene fronteras con casi todos los países de la región. La Unión de Naciones Sudamericanas es la concreción actual de una prioridad de Brasil, que finalmente ha sido acompañada por los otros países y que posibilita otorgar un marco sudamericano para determinados temas esenciales, que requieren en el presente de un tratamiento concertado. De esta forma, Unasur posibilita bases para que la región sudamericana tenga voz en el sistema internacional, pero también para que se plantee la participación de la región en el delicado tema de la gobernanza global.

Brasil, como principal articulador entre el Mercosur-Unasur y de los distintos ámbitos en que evoluciona la región sudamericana (y no solo el Mercosur), tiene particular interés en responder a los desafíos que plantea la globalización, a través de dichos ámbitos, lo cual implica tener resultados positivos. Es justamente la (buena) gobernanza regionalsudamericana la que otorga bases sustentables a Brasil para su participación en la gobernanza global. De ahí que el actual estancamiento del Mercosur no debería prolongarse por mucho tiempo, aun cuando el mismo sea funcional a la estrategia de Brasil, ya que puede mostrar que los temas sustantivos se encuentran en la agenda regional para la resolución.

En definitiva, durante la segunda década del siglo XXI asistiremos a definiciones claves en lo que concierne al proceso regional del Mercosur. Una de las perspectivas posibles es que Brasil pueda continuar articulando los dos espacios regionales -MercosurUnasur-, pautando los avances en ambos ámbitos y acompasando los mismos con los de la gobernanza global. Como la inversión de las prioridades del regionalismo estratégico actual, en cuanto al ámbito de referencia para la elaboración y la construcción de contenidos de la gobernanza sudamericana y global, es lo nacional-local, otra perspectiva posible es que finalmente se tenga un escenario de nacionalismos y localismos frente a la globalización. Claro que entre estos dos escenarios queda un margen amplio para el papel articulador que puedan jugar Brasil y Argentina, y en menor medida el resto de países y para lo que otros actores, incluyendo a la sociedad civil nacional-regional puedan diseñar y llegar a construir.

\section{REFERENCIAS}

Axline, Andrew. 1996. "Regionalismo latinoamericano en la era de la globalización." Pp. 3452 en La inserción internacional del MERCOSUR. ¿Mirando al Sur o mirando al Norte?, editado por Lincoln Bizzozero y Marcel Vaillant. Montevideo: ARCA. 
Bernal-Meza, Raúl. 2008. "Argentina y Brasil en la política internacional: regionalismo y Mercosur (estrategias, cooperación y factores de tensión)." Revista Braileria de política internacional 51(2):154-78.

Bilbao, Luis. 2000. "Brasil tentado por una opción sudamericana." Le Monde Diplomatique II (13):1,4-5.

Bizzozero, Lincoln. 2001. "Los primeros diez años del Mercosur. Repensando los pilares y las aristas de la construcción.” Cuadernos del SELA 62:177-99.

. 2003. "Los cambios de gobierno en Argentina y Brasil y la conformación de una agenda del Mercosur." Nueva Sociedad 186:128-42.

. 2007a. "Las relaciones Mercosur-Unión Europea: la gobernanza europea frente a los cambios en el bloque sudamericano." Consultado mayo 23, 2012. (http://www.reseauamerique-latine.fr/ceisal-bruxelles/INT/INT-3-BIZZOZERO.pdf).

. 2007b. "La cuestión institucional en procesos de integración regional: la delicada construcción del Mercosur." Pp. 169-88 en Los nuevos escenarios en la dinámica de la integración suramericana, comp. por José Briceño Ruiz y Nebis Acosta Kanquis. Maracaibo: Banco Central de Venezuela (subsede Maracaibo) Universidad del Zulia, Centro Experimental de Estudios Latinoamericanos (CEELA), CEFI-CELAC.

2009a. "Integración regional en el Cono Sur 1980-2007. Mercosur como respuesta estratégica." Pp. 170-207 en Fin de época: de la integración tradicional al regionalismo estratégico, editado por Alfredo Guerra Borges. México D.F.: Siglo XXI.

. 2009b. "Contenido y funcionalidad de BRIC y UNASUR en la política internacional de Brasil.” VIII Jornadas de Investigación de la Facultad de Ciencias Sociales, Universidad de la República. Montevideo, septiembre.

. 2009c. "Brasil en el imaginario colectivo de la sociedad uruguaya. Líder regional, mercado potencial o gigante en expansión?” Revista Densidades 4:19-34.

Briceño, José. 2006. "Regionalismo estratégico e interregionalismo en las relaciones externas del Mercosur." Revista Aportes para la Integración Latinoamericana XII (15):28-42.

Caetano, Gerard, coord. 2009. La reforma institucional del Mercosur. Del diagnóstico a las propuestas. Montevideo: CEFIR, Tricel ediciones. 
Camargo, Sonia de. 1999. "Formas de Governança no Contexto da Globalização." Contexto Internacional 21 (2):225-57.

Cervo, Amado. 1994. "Política exterior e desenvolvimento: Estados Unidos, Brasil e Argentina nos dois últimos séculos.” Pp. 358-67 en Relaçòes Internacionais dos países americanos. Vertentes da História, editado por Amado Cervo y Wolfgang Döpcke. Brasilia: Universidad de Brasilia.

Cimadamore, Alberto y Adriana Rodríguez. 2008. "Unasur: objetivos y viabilidad institucional de la integración." Densidades 2:7-24.

Deblock, Christian y Brunelle Dorval. 1993. "Une intégration régionale stratégique: le cas nord-américain." Revue Etudes Internationales XXIV (3):595-629.

Devés, Eduardo. 2003. El pensamiento latinoamericano en el siglo XX. Desde la CEPAL al neoliberalismo. Tomo II. Buenos Aires: Centro de Investigaciones Diego Barros Arana, Biblos.

Giacalone, Rita. 2005. "La Comunidad Sudamericana de Naciones: una alianza entre izquierda y empresarios." Nueva Sociedad 202:74-86.

Guilhon, José. 2000. "La nueva geometría del poder mundial en las visiones argentina y brasileña." Pp. 79-114 en El futuro del Mercosur. Entre la retórica y el realismo, compilado por Felipe de la Balze. Buenos Aires: Consejo Argentino para las Relaciones Internacionales, Asociación de Bancos de la Argentina.

Herrera, Jorge. 1995. "Las políticas exteriores de la Argentina y de Brasil: divergencias y convergencias." Serie Documentos de Trabajo 10. Buenos Aires: ISEN.

Hettne, Björn. 1994. “The New Regionalism: Implications for Development.” Pp. 1-45 en The New Regionalism. Implications for Global Development and International Security, editado por Björn Hettne y Andreas Inotai. Helsinki: The United Nations University, Wider.

Hettne, Björn, András Inotai y Osvaldo Sunkel. 2000. National perspectives on the new regionalism in the South. Londres: St. Martin's Press, Mac. Millan Press.

Hirst, Mónica. 2009. "Las relaciones Brasil-Estados Unidos: al compás de nuevas coincidencias." Foreign Affairs Latinoamérica 9 (2):33-42.

Luján, Carlos. 2009. "Una reflexión sobre los soportes institucionales para viabilizar políticas públicas regionales." Pp. 183-97 en La reforma institucional del Mercosur. Del diagnóstico a las propuestas, coordinado por Gerardo Caetano. Montevideo: CEFIR, Tricel editores. 
Malamud, Carlos. 2007. "El Mercosur y Venezuela: la cumbre de Asunción y el impacto de una posible ruptura venezolana.” Real Instituto Elcano. Consultado mayo 23, 2012 (http:// www.almendron.com/tribuna/16387/el-mercosur-y-venezuela-la-cumbre-de-asuncion-y-elimpacto-de-una-posible-ruptura-venezolana/).

Mellado, Noemí. 1998. "Una asignatura pendiente del Mercosur: la participación social." Aldea Mundo 6:71-78.

Messner, Dirk. 2000. Desafíos de la globalización. Lima: Friedrich Ebert Stiftung.

Moniz, Luiz. 2004. Argentina, Brasil y Estados Unidos. De la triple alianza al Mercosur. Buenos Aires: Grupo Editorial Norma.

Roett, Riordan, comp. 1999. Mercosur: Integración regional y mercados mundiales. Buenos Aires: Nuevo Hacer, Grupo Editor Latinoamericano.

Ruiz, Ariela. 2008. Unasur y el desafío de sentirse sudamericano. Programa de las Américas, Columna. Consultado junio 10, 2011, (www.ircamericas.org/esp/5287).

Vigevani, Tullo y Haroldo Ramanzini jr. 2009. "Brasil en el centro de la integración.” Nueva Sociedad 219:76-96. 